\title{
Purification and characterization of the extracellular aspartyl proteinase of Candida albicans: removal of extraneous proteins and cell wall mannoprotein and evidence for lack of glycosylation
}

\author{
Christine J. Morrison, ${ }^{1 *}$ Steven F. Hurst, ${ }^{1}$ Sandra L. BragG, ${ }^{1}$ Randall J. Kuykendall, ${ }^{1}$ \\ Humberto Diaz, ${ }^{2}$ David W. McLaughlin ${ }^{1}$ and Errol Reiss ${ }^{1}$ \\ ${ }^{1}$ Division of Bacterial and Mycotic Diseases, National Center for Infectious Diseases, Centers for Disease Control, \\ Atlanta, Georgia 30333, USA \\ ${ }^{2} 21$ st Century Children's Hospital, Mexico City, Mexico
}

(Received 28 October 1992; accepted 27 January 1993)

\begin{abstract}
Aspartyl proteinase (AP) is an extracellular enzyme of Candida albicans implicated as a pathogenic factor. Previous reports on the purification and characterization of AP suggested that a single DEAE-Sephadex chromatographic step was sufficient for the removal of extraneous proteins and that the final product was glycosylated. We purified AP using a chromatographic series consisting of DEAE-Sephadex A25, Sephadex G75 and rechromatography on DEAE-Sephadex A25. Use of DEAE-Sephadex alone did not remove extraneous proteins and removed little contaminating mannoprotein (MP). The addition of a Sephadex G75 column to the purification scheme removed the majority of contaminating MP and proteins. The final DEAE-Sephadex A25 chromatographic step resulted in (a) removal of detectable extraneous proteins, $(b)$ removal of immunologically detectable MP by dot blot and Western blot enzyme immunoassay, $(c)$ loss of periodic acid-silver stain positivity, and (d) a high AP yield (1295 $\left.\mathrm{U} \mathrm{I}^{-1}\right)$ and specific activity (1749 $\left.\mathrm{U} \mathrm{mg}^{-1}\right)$. We conclude that a single DEAESephadex A25 purification step is insufficient to remove extraneous proteins and MP, which could interfere with the production of AP-specific antibodies and the dissection of moieties responsible for immune reactivity. Reports of periodic acid-Schiff or anthrone positivity of AP preparations may reflect the presence of extraneous MP, which can be removed by the chromatographic series we describe.
\end{abstract}

\section{Introduction}

Candida albicans is an opportunistic fungus responsible for increasing morbidity and mortality in the immunocompromised host (Reingold et al., 1986; Richardson, 1991). Characteristics associated with the pathogenicity of this normally benign, endogenous commensal include predisposing host factors (Morrison et al., 1986; Odds, 1988), conversion from the yeast to the pseudohyphal form (Barnes et al., 1983; Anderson \& Odds, 1985), increased adherence to epithelial or mucous membranes (McCourtie \& Douglas, 1984; Ghannoun \& Abu Elteen, 1986) and the production of an extracellular aspartyl proteinase (AP) [EC 3.4.23.6] (Staib, 1969; Macdonald \& Odds, 1980; Kwon-Chung et al., 1985).

*Author for correspondence. Tel. (404) 639 3128; fax (404) 639 3296.

Abbreviations: AP, aspartyl proteinase; EIA, enzyme immunoassay; MP, mannoprotein; NCB, citric acid-sodium citrate buffer; PA-SS, periodic acid-silver stain; PAS, periodic acid-Schiff stain.
The use of AP for the immunodiagnosis of candidal antigenaemia has been described (Rüchel \& Böning, 1983; Rüchel et al., 1988). The advantage of a test using a pathogenic factor as a marker for infection lies in its potential to differentiate between simple colonization and invasive disease. However, antibodies used in these tests are only as specific as the purity of the antigen used to elicit them. Therefore, AP should be free of contaminating cell wall mannoprotein (MP) and extraneous proteins that could reduce specificity. In addition, studies to dissect epitopes responsible for immune responsiveness or to delineate the pathogenic mechanism(s) of AP could be complicated by impure AP preparations.

Several methods to purify AP from crude culture supernatants have been described (Macdonald \& Odds, 1980; Rüchel, 1981; Negi et al., 1984; Ray \& Payne, 1990). The resultant products demonstrated carbohydrate positivity either by anthrone reactivity (Macdonald \& Odds, 1980) or by periodic acid-Schiff (PAS) staining (Rüchel, 1981; Negi et al., 1984; Ray \& Payne, 1990). Antibodies against such preparations may 
therefore recognize carbohydrate as well as protein moieties. Since carbohydrate epitopes are often responsible for cross-reactivity among unrelated fungi, antibodies raised to these common entities could confuse diagnosis (Hellwege et al., 1972; Taschdjian et al., 1973). The ubiquitous presence of $C$. albicans MP in culture supernatants (Kaufman \& Reiss, 1992) complicates the production of monospecific anti-AP antibodies unless measures are taken to remove immunologically reactive MP. In addition, MP may down-regulate the immune response (Domer \& Garner, 1989; Garner et al., 1990), thereby complicating studies examining immune responsiveness to AP and its role in pathogenesis.

To eliminate the possible complications associated with the presence of contaminating proteins and MP in AP preparations, we describe the detection and removal of chemically and immunologically detectable MP and extraneous proteins from AP preparations.

\section{Methods}

Micro-organism. Lyophilized stock cultures of $C$. albicans strains CBS 2730 (a gift from R. Rüchel, University of Gottingen, FRG; a variant of the type-strain also known as DSM 6659), 36B (a gift from P. Auger, University of Montreal, Quebec, Canada) and B311 (Mycotic Diseases Branch, Centers for Disease Control culture collection) were used. Blastoconidia were grown on Sabouraud glucose agar slants (BBL) for $48 \mathrm{~h}$ at $25^{\circ} \mathrm{C}$, harvested, washed by centrifugation in $0.01 \mathrm{M}$ phosphate buffered saline PBS; $0 \cdot 11 \%$ (w/v) $\mathrm{Na}_{2} \mathrm{HPO}_{4}, 0.032 \% \mathrm{NaH}_{2}$ $\mathrm{PO}_{4} \cdot \mathrm{H}_{2} \mathrm{O}, 0.85 \% \mathrm{NaCl}, \mathrm{pH} 7.2$, and resuspended in PBS. For extracellular production of AP, blastoconidia $\left(7.5 \times 10^{6} \mathrm{ml}^{-1}\right)$ were grown in yeast carbon base broth (Difco) containing vitamins $\left(0.1 \mu \mathrm{ml}^{-1}\right.$, IsoVitaleX enrichment, BBL) and $0.2 \%(\mathrm{w} / \mathrm{v})$ each of glucose and BSA (fraction V, Sigma), adjusted to $\mathrm{pH} 5 \cdot 6$. Cultures ( $300 \mathrm{ml}$ medium in each of ten 1 litre Erlenmeyer flasks) were rotated at 140 r.p.m., $25^{\circ} \mathrm{C}$ for $8-14$ days (Lam et al., 1991). Selected flasks received $0.5-5 \mu \mathrm{g}$ tunicamycin $\mathrm{ml}^{-1}$ (Calbiochem), predissolved in ethanol, to inhibit glycosylation (Duksin \& Mahoney, 1982).

Proteinase activity assay. AP activity in culture supernatants was tested daily. Enzyme activity was determined spectrophotometrically following the digestion of BSA as substrate as described by Crandall \& Edwards (1987). To $0.5 \mathrm{ml}$ culture supernatant, $2.0 \mathrm{ml} 1 \%$ (w/v) BSA in $0.1 \mathrm{M}$-citric acid-sodium citrate buffer (NCB), $\mathrm{pH} 3.5$, was added, and the mixture was incubated at $37^{\circ} \mathrm{C}$ for $30 \mathrm{~min}$. The reaction was then stopped by adding $5 \cdot 0 \mathrm{ml}$ ice-cold $10 \%(\mathrm{w} / \mathrm{v})$ TCA. Precipitated protein was removed by centrifugation at $1500 \mathrm{~g}$ for $10 \mathrm{~min}$ followed by filtration through a $0.45 \mu \mathrm{m}$ porosity filter (Millex-HA, Millipore). The amount of proteolysis was determined by measuring the $A_{280}$ of the filtrate.

Control tubes containing $0.5 \mathrm{ml}$ culture supernatant were incubated for $30 \mathrm{~min}$ at $37^{\circ} \mathrm{C}$, followed by the addition of $5.0 \mathrm{ml} \mathrm{TCA}$ and then $2.0 \mathrm{ml}$ BSA. One unit (U) of AP activity was defined as equal to a change in $A_{280}$ of $0.1 \mathrm{ml}^{-1}(30 \mathrm{~min})^{-1}$, at $\mathrm{pH} 3.5$ and $37^{\circ} \mathrm{C}$. One unit of AP activity corresponded to $0.7 \mathrm{U}$ of proteinase A activity from Saccharomyces cerevisiae [endopeptidase, (EC 3.4.23.6, Sigma) resuspended to $1 \mathrm{mg} \mathrm{ml}^{-1}$ and assayed for BSA digestion (Crandall \& Edwards, 1987)]

Purification of AP. Purification procedures were conducted at $4{ }^{\circ} \mathrm{C}$. When AP activity reached a maximum (after 8-10 days of culture), culture supernatant was collected by centrifugation at $1500 \mathrm{~g}$ for $30 \mathrm{~min}$, filtered through a $0.45 \mu \mathrm{m}$ porosity membrane (Nalge) and concentrated 10 -fold in a 31 ultrafiltration unit containing a YM-10 membrane (Amicon Corporation). The retentate was dialysed overnight [12 000-14000 kDa molecular mass cut-off dialysis tubing, (Spectra/por, Fisher Scientific)] against 31 of $0.02 \mathrm{M}-\mathrm{NCB}, \mathrm{pH} 6.3$.

A DEAE-Sephadex A25 (Pharmacia LKB) column $(2 \times 25 \mathrm{~cm})$ was packed to $40 \mathrm{ml}$ capacity and equilibrated to $\mathrm{pH} 6 \cdot 3$ and a conductivity of $4.4 \mathrm{~m} \Omega^{-1}$. Dialysed retentate $(300 \mathrm{ml})$ was applied to the column at $33 \mathrm{ml} \mathrm{h}^{-1}$ and washed in with $175 \mathrm{ml}$ of column buffer. Elution buffer (0.2 M-NCB, pH 6.3) was applied, and $5 \mathrm{ml}$ fractions were collected. Fractions from the resultant single $A_{280}$ peak, containing maximum AP activity (fractions 6-10 following application of $0 \cdot 2 \mathrm{M}-\mathrm{NCB}$ ), were pooled $(25 \mathrm{ml})$ and concentrated to $2.5 \mathrm{ml}$ by ultrafiltration through a YM-10 membrane.

Concentrated, pooled fractions from the DEAE-Sephadex A25 column were applied to a Sephadex G75 column. The column $(1.7 \times 85 \mathrm{~cm}$ of packed gel $)$ was equilibrated with $0.02 \mathrm{M}-\mathrm{NCB}$, charged with the sample, and eluted with $0.02 \mathrm{M}-\mathrm{NCB}, \mathrm{pH} 6 \cdot 3$, at a flow rate of $32.5 \mathrm{ml} \mathrm{h}^{-1}$. Fractions of $5.5 \mathrm{ml}$ were collected. Two $A_{280}$ peaks were observed: a smaller peak eluted between fractions 7 and 9 , and a larger peak, containing the majority of AP activity, eluted in fractions 10-16. Fractions 10-16 were pooled and rechromatographed on a second DEAE-Sephadex A25 column.

The second DEAE-Sephadex A25 column $(1 \times 15 \mathrm{~cm})$ was packed with $8 \mathrm{ml}$ of gel, equilibrated with $0.02 \mathrm{M}-\mathrm{NCB}, \mathrm{pH} 6.3$, and charged with pooled fractions from the G75 column. The flow rate was $16.2 \mathrm{ml}$ $\mathrm{h}^{-1}$, and $2.7 \mathrm{ml}$ fractions were collected. The sample was washed into the column with 2.5 column vols of $0.02 \mathrm{M}-\mathrm{NCB}, \mathrm{pH} 6.3$, and a linear gradient of $0.02-0.4 \mathrm{M}-\mathrm{NCB}, \mathrm{pH} \mathrm{6.3}$, was applied at a flow rate of $16.2 \mathrm{ml} \mathrm{h}^{-1}$. A single $A_{280}$ peak containing AP activity eluted in fractions 3-10.

Pepstatin A-agarose column chromatography. Pepstatin A-agarose chromatography was performed by a modification of the method of Kregar et al. (1977). Concentrated culture supernatant $(20 \mathrm{ml})$ was dialysed against $0 \cdot 1 \mathrm{M}$-sodium acetate buffer, $\mathrm{pH} 3 \cdot 5$, containing $1 \mathrm{M}$ $\mathrm{NaCl}$ and passed through a pepstatin A-agarose (Sigma) column $(5 \mathrm{ml}$ gel in a $0.7 \times 13 \mathrm{~cm}$ column) at a rate of $15 \mathrm{ml} \mathrm{h}^{-1}$. Bound sample was eluted with $0.1 \mathrm{M}$-Tris $/ \mathrm{HCl}$ buffer, $\mathrm{pH} 8.6$, containing $1 \mathrm{M}-\mathrm{NaCl}$. Fractions ( $5 \mathrm{ml}$ each) were collected into tubes containing $1.0 \mathrm{ml}-0 \cdot 1 \mathrm{M}-$ sodium acetate buffer, $\mathrm{pH} 3 \cdot 5$, to acidify the samples.

SDS-PAGE and immunoblotting. Proteinase samples containing $1 \%$ SDS, $0.01 \mathrm{M}$-DTT, $10 \%$ (v/v) glycerol, and $0.025 \%$ bromophenol blue were heated at $100{ }^{\circ} \mathrm{C}$ for $5 \mathrm{~min}$ prior to SDS-PAGE. Electrophoresis was conducted using a PhastSystem apparatus, pre-cast $(4.5 \times 5 \mathrm{~cm})$ $8-25 \%$ gradient gels, and SDS buffer strips (Pharmacia LKB).

Alternatively, electrophoresis was performed with a discontinuous Tris/borate/sulphate/chloride buffer (Tsang et al., 1983) using $10 \%$ homogeneous polyacrylamide gels (dimensions: $160 \times 180 \times 0.75 \mathrm{~mm}$ ) and a Hoefer Scientific (Model SE 400) electrophoresis apparatus. The SDS-PAGE-resolved bands were stained with silver (Tsang, 1987), or to detect carbohydrate-containing protein bands, a periodic acid modification of the silver stain was used (PA-SS: Dubray \& Bezard, 1982; Tsai \& Frasch, 1982). This method was reported to be 500-times more sensitive than PAS staining to detect carbohydrate (Tsai \& Frasch, 1982).

PhastSystem SDS-PAGE-resolved bands were transferred electrophoretically to nitrocellulose $(0.2 \mu \mathrm{m}$ porosity, Schleicher and Schuell), and blots were developed by enzyme immunoassay (EIA) as described by Tsang et al. (1986).

Dot blot EIAs (dot EIAs) were conducted as described by TodaroLuck et al. (1989), except that nitrocellulose strips were dotted with purified (Peat et al., 1961) MP (1.0, 0.1 or $\left.0.01 \mathrm{mg} \mathrm{m}^{-1}\right)$ or products of AP purification steps. The mean amount of protein dotted was $284 \pm$ 
$10 \mu \mathrm{g} \mathrm{ml}^{-1}(n=4)$ except for the following samples: MP peak from Sephadex $\mathrm{G} 75,117 \mu \mathrm{g} \mathrm{ml}^{-1}$; peak fraction from secondary DEAESephadex A25 ( ${ }^{\circ} \mathrm{D}$ peak), $136 \mu \mathrm{g} \mathrm{m}^{-1}$; and pooled, concentrated fractions from secondary DEAE-Sephadex A25 ( $2^{\circ}$ DEAE 2), $635 \mu \mathrm{g} \mathrm{ml}^{-1}$. These were tested with horseradish peroxidase-labelled polyclonal anti-AP antibodies (1:250 dilution, described below), monoclonal IgM anti-MP (CB6-AB11, 1:250), or monoclonal IgG anti-MP (DC5-CD10, 1:500) (Reiss et al., 1986). Polyclonal rabbit anti-C. albicans cell-wall IgG (Reiss et al., 1974) was used in indirect dot EIA $(1: 2000)$ with peroxidase-labelled goat anti-rabbit IgG as indicator antibody (1:1000, $\gamma$-specific, Hyclone).

Immunization of mice with AP. Purified AP, in Freund's complete adjuvant, was used to immunize female CFW mice (Charles River Laboratories, Wilmington, MA, USA). Mice were immunized by intraperitoneal (i.p.) injection of $0.1 \mathrm{ml}$ antigen-adjuvant emulsion containing $20 \mu \mathrm{g}$ purified AP and boosted twice by i.p. injection of $10 \mu \mathrm{g}$ purified AP in Freund's incomplete adjuvant at 2-week intervals. Mice were bled biweekly, and those testing positive for anti-AP antibodies by immunoblot analysis were injected i.p. with sarcoma $180 /$ TG cells to induce antibody-containing ascitic fluid (Sartorelli et al., 1966). Immunoglobulin was purified from ascitic fluid by a modification of previously described methods (Reiss et al., 1977). Briefly, ascitic fluid was fractionated by ammonium sulphate precipitation $\left[35 \%\left(\mathrm{NH}_{4}\right)_{2} \mathrm{SO}_{4}\right.$ saturation followed by $50 \%$ saturation of the non-precipitated material], and IgG fractions were isolated by DEAE-Sephadex A25 column chromatography using $0 \cdot 1 \mathrm{M}-\mathrm{Tris} / \mathrm{HCl}$ buffer, $\mathrm{pH} 8 \cdot 2$, containing $0 \cdot 1 \mathrm{M}-\mathrm{NaCl}$ (Reiss et al., 1977). IgG fractions were then dialysed versus $0 \cdot 1 \mathrm{M}$-PBS, $\mathrm{pH} 7 \cdot 2$, bound to protein $\mathrm{A}$, and desorbed with $0 \cdot 1 \mathrm{M}$-sodium citrate buffer, $\mathrm{pH} 4 \cdot 0$. Fractions were collected into $0.5 \mathrm{M}$-potassium phosphate buffer, $\mathrm{pH} 8.0$, to neutralize samples before pooling of IgG peak fractions, concentration by ultrafiltration (YM-30 membrane), and dialysis versus PBS.

Double antibody sandwich EIA for MP detection. MP was detected in AP preparations by using a double antibody sandwich EIA (Kaufman \& Reiss, 1992)

Protein determinations. Total protein was determined by the method of Bradford (1976) using a commercial reagent (Bio-Rad) and human albumin/globulin (Sigma) as standard. Chromatograms of column fractions were depicted such that $100 \%$ transmittance was equivalent to an $A_{280}$ of $2 \cdot 00$.

Statistical analyses. Student's $t$-test was used to determine significant differences between experimental means. Values were expressed as the arithmetic mean plus or minus the standard error of the mean for the number of experiments designated. A $P$ value of $\leqslant 0.05$ was considered significant.

\section{Results}

\section{Isolation and purification of $A P$}

Various methods have been employed to purify AP from crude culture supernatants. In each case, the purified product was PAS- or anthrone reaction-positive, suggesting that AP was a glycoprotein (Macdonald \& Odds, 1980; Rüchel, 1981; Negi et al., 1984; Ray \& Payne, 1990). In addition, depending upon the purification procedure used, various numbers of protein bands in the final purified preparation were detected by SDS-PAGE. We chose a purification method modified from the original protocol of Remold et al (1968) because that method was the only one that obtained a single AP band as the result of systematic removal of other proteins.

\section{Primary DEAE-Sephadex A25 chromatography}

Fig. 1( $a$ ) shows the $A_{280}$ elution profile obtained from the primary DEAE-Sephadex A25 column and the AP activity for each fraction. A single chromatographic peak, corresponding to maximum AP activity, was obtained.

SDS-PAGE of primary DEAE-Sephadex A25 fractions conducted using the PhastSystem revealed a prominent protein in the predicted (Rüchel, 1981; Negi et al., 1984; Ross et al., 1990) range of $42-44 \mathrm{kDa}$ (Fig. $1 b$, lanes 6-10). Bands of lesser intensity appeared immediately above and below this protein in fraction 6 (Fig. $1 b$ ), where peak AP activity occurred (Fig. $1 a$ ). Co-
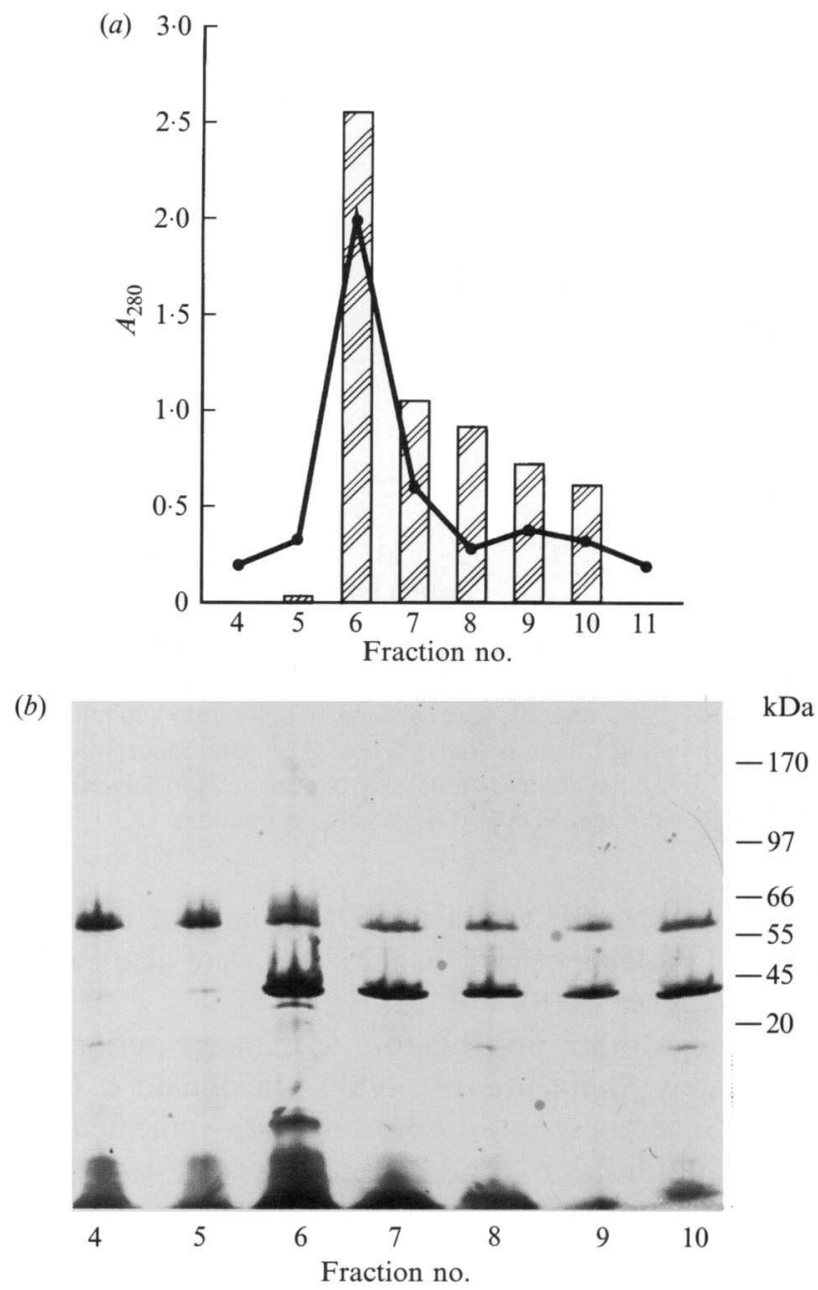

Fig. 1. Primary DEAE-Sephadex A25 column chromatography of supernatant from an 8-day culture of strain CBS 2730. (a) UV flow analysis (line) and AP activity $\left[\mathrm{ml}^{-1}(30 \mathrm{~min})^{-1}\right]$ of the corresponding column fractions (bars). (b) Silver-stained gel from PhastSystem SDSPAGE of column fractions. 

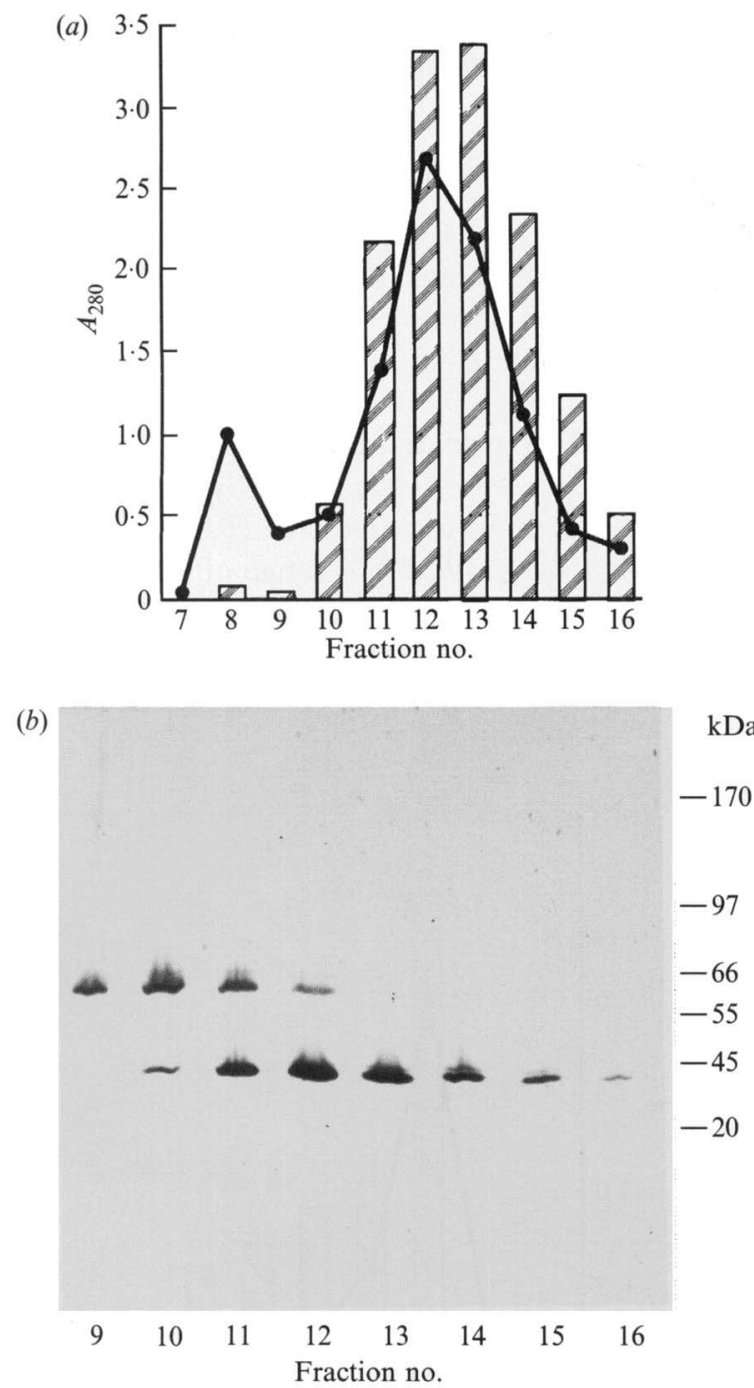

Fig. 2. Sephadex G75 column chromatography of pooled AP fractions from primary DEAE Sephadex A25 column chromatography shown in Fig. 1. (a) UV flow analysis (line) and AP activity $\left[\mathrm{ml}^{-1}(30 \mathrm{~min})^{-1}\right]$ of the corresponding fractions (bars). Total $A_{280}$ absorbance values are multiplied by six to accommodate axis dimensions. (b) Silver-stained gel from PhastSystem SDS-PAGE of column fractions.

purifying with AP was a $60 \mathrm{kDa}$ protein of unknown activity. Proteins of less than $20 \mathrm{kDa}$ were also evident (Fig. 1b, lanes 4-10).

Although other investigators terminated purification at this step (Shimizu et al., 1987; Macdonald \& Odds, 1980; Ganesan et al., 1991), our data indicated that further purification of AP was necessary to remove extraneous proteins.

\section{Sephadex G75 chromatography}

Pooled fractions from the primary DEAE-Sephadex A25 column containing AP activity (fractions 6-10) were concentrated 10-fold and applied to a Sephadex G75 sizing column. The chromatogram and AP activity for the collected fractions are shown in Fig. 2(a). Two absorption peaks were obtained: the smaller peak, eluting first, contained minor AP activity $[3.4 \pm 0.4 \mathrm{U}(\mathrm{mg}$ protein $\left.)^{-1}, n=4\right]$, and the larger peak contained major AP activity [1448 $\pm 243 \mathrm{U}$ (mg protein $\left.)^{-1}, n=7\right]$.

SDS-PAGE using the PhastSystem (Fig. $2 b$ ) demonstrated that the Sephadex G75 column removed low molecular mass protein contaminants but retained the previously observed $60 \mathrm{kDa}$ protein in the nascent fractions (fractions 9-12), including one fraction containing maximum AP activity (fraction 12). A $43 \mathrm{kDa}$ protein was observed in fractions derived from the second AP-containing peak, whereas the smaller peak (fractions 7-9) did not contain detectable protein at $43 \mathrm{kDa}$ (Fig. $2 b$ ). Large format SDS-PAGE of pooled fractions from each of the two peaks confirmed the presence of the $43 \mathrm{kDa}$ protein in the larger peak and its absence from the smaller peak. It also revealed a smear of high molecular mass material at the top of the gel $(>71 \mathrm{kDa})$ for pooled fractions from the smaller peak only (data not shown). This dispersed material at the top of the gel may be contaminating MP because the smaller peak contained approximately 50-times more MP $\left[341 \pm 63 \mathrm{ng}(\mu \mathrm{g} \text { protein })^{-1}, n=4\right]$ than the second peak $\left[6 \cdot 1 \pm 1.2 \mathrm{ng} \quad(\mu \mathrm{g} \text { protein })^{-1}, \quad n=4, \quad P<0.025\right]$, as determined by sandwich EIA.

MP peaks were also observed after Sephadex G75 chromatography of AP when two other strains (36B and B311) of C. albicans were used. These observations indicate that the Sephadex G75 column not only removes extraneous low molecular mass proteins but also contaminating MP. Use of Sephadex G75 first, followed by DEAE-Sephadex A25 (Remold et al., 1968), resulted in no resolution of AP from MP and a lower AP yield (342 $\mathrm{U}$ total activity, $500 \mathrm{U} \mathrm{mg}^{-1}$ specific activity, and $55 \cdot 4 \%$ recovery of total units).

\section{Secondary DEAE-Sephadex A25 chromatography}

Pooled AP-rich fractions from the Sephadex G75 column were rechromatographed using a second DEAE-Sephadex A25 column. Chromatography yielded a single $A_{280}$ peak corresponding to maximum AP activity (Fig. $3 a$ ). PhastSystem SDS-PAGE of the fractions (Fig. $3 b$ ) indicated that this purification step removed the $60 \mathrm{kDa}$ protein (smudge above fractions $4-6$, Fig. $3 b$, is not lane-associated, and is an artifact not seen in subsequent gels) and yielded a single $43 \mathrm{kDa}$ protein in fractions corresponding to maximum AP activity. Pooled peak fractions (4-10) from the second DEAE-Sephadex A25 column were concentrated 10 -fold by ultrafiltration and will be referred to as 'purified AP.'

Purified AP contained an average of $0 \cdot 6 \pm 0 \cdot 1 \mathrm{ng}$ MP 

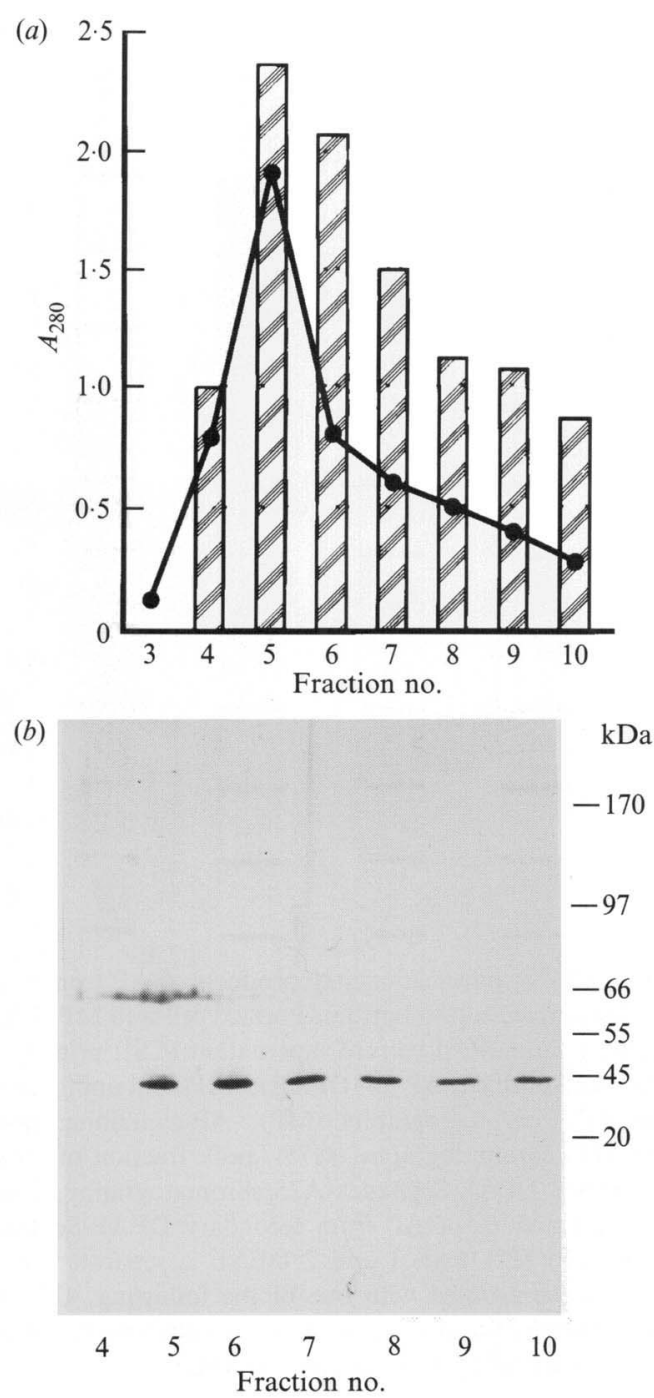

Fig. 3. Secondary DEAE-Sephadex A25 column chromatography of pooled peak AP fractions from Sephadex G75 column chromatography shown in Fig. 2. (a) UV flow analysis (line) and AP activity $\left[\mathrm{ml}^{-1}\right.$ $(30 \mathrm{~min})^{-1}$ ] of the corresponding fractions (bars). Total $A_{280}$ absorbance values are multiplied by six to accommodate axis dimensions. (b) Silver-stained gel from PhastSystem SDS-PAGE of column fractions.

$(\mu \mathrm{g} \text { protein })^{-1}$ (range $0-1 \cdot 0 \mathrm{ng} \mu \mathrm{g}^{-1}, n=5$ ). Thus, Sephadex G75 chromatography removed the majority of contaminating MP ( $98.5 \%$ removal relative to unpurified culture supernatants; range $97-100 \%$ ), whereas the second DEAE-Sephadex A25 column removed additional MP (i.e. purified AP versus AP after Sephadex G75 chromatography contained 10-fold less MP after the final purification step: $0.6 \mathrm{ng} \mu \mathrm{g}^{-1}$ vs. $6.1 \mathrm{ng}_{\mu \mathrm{g}}^{-1}$, $P=0.025$ ). The quantity of MP present in purified AP was therefore less than $0.06 \%$ of the total product.

The total yield of purified AP recovered was $1295 \mathrm{U}$ $1^{-1}$ (or $0 \cdot 7 \pm 0.1 \mathrm{mg} \mathrm{I}^{-1}$ ) of culture medium or $3884 \mathrm{U}$ $(2 \cdot 22 \mathrm{mg})$ per 31 batch culture (specific activity,
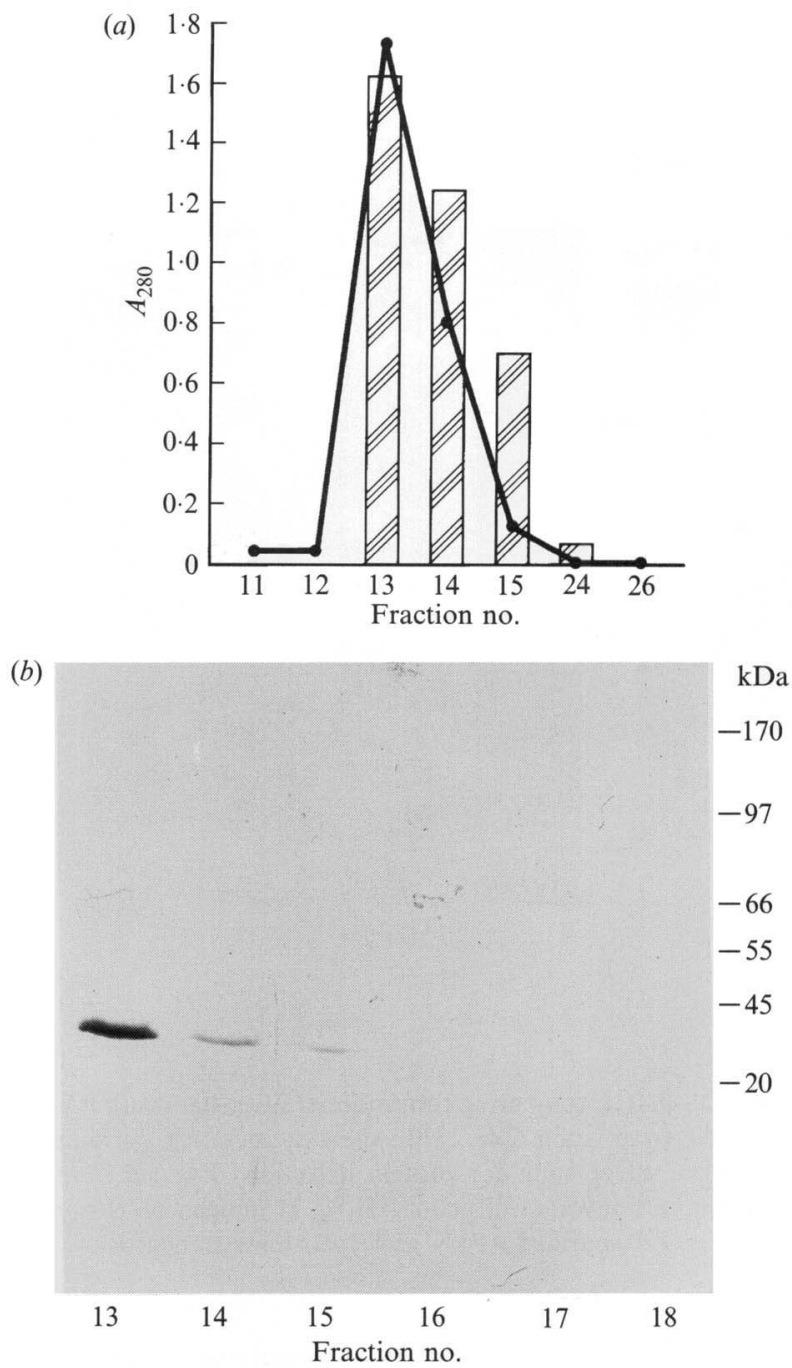

Fig. 4. Pepstatin A-agarose column chromatography of supernatant from 8-day culture of strain CBS 2730. (a) UV flow analysis (line) and AP activity $\left[\mathrm{ml}^{-1}(30 \mathrm{~min})^{-1}\right]$ of the corresponding column fractions (bars). (b) Silver-stained gel from PhastSystem SDS-PAGE of column fractions.

$1749 \pm 390 \mathrm{U} \mathrm{mg}^{-1}, n=8$ ). This represents a $339 \%$ or 4.4-fold increase in specific activity relative to unpurified AP from culture supernatants.

\section{Purification of AP by pepstatin A-agarose chromatography}

Alternatively, a pepstatin A-agarose column was used to purify AP. Pepstatin A inhibits AP activity through its specific binding to the active site of aspartyl proteinases (Rüchel, 1981). Pepstatin A-agarose chromatography of unpurified culture supernatant yielded a single chromatographic peak corresponding to maximum AP activity (Fig. $4 a$ ) and a single $43 \mathrm{kDa}$ protein by PhastSystem SDS-PAGE (Fig. $4 b$ ). 


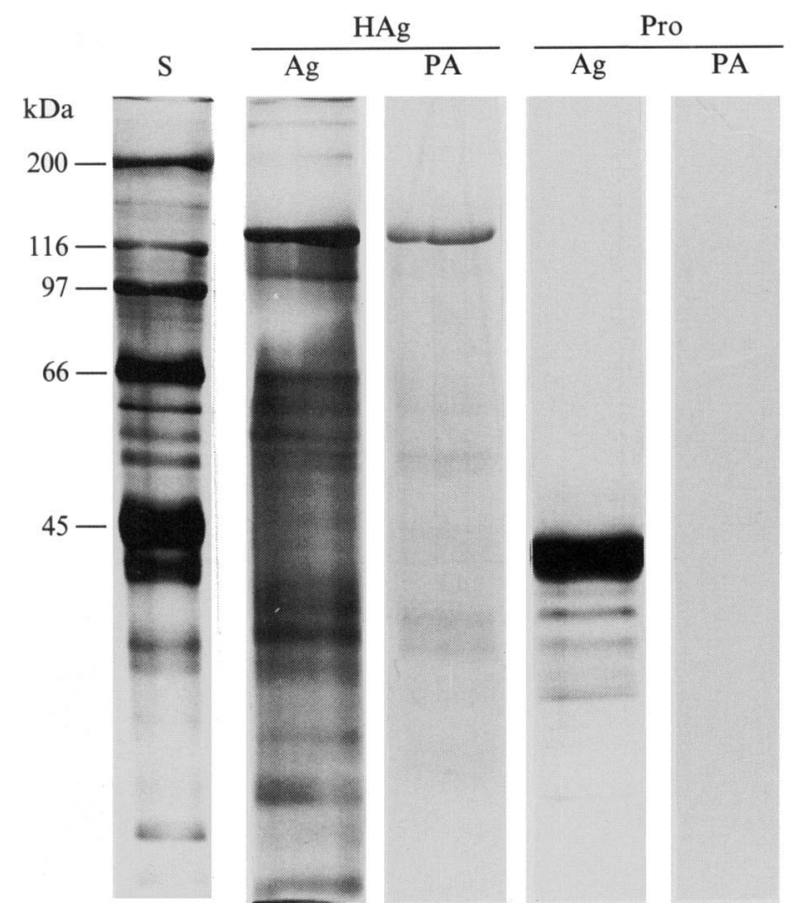

Fig. 5. SDS-PAGE comparing conventional silver stain with PA-SS of purified AP from strain CBS 2730. Abbreviations: Ag, gel stained by conventional silver stain for protein detection; PA, gel stained by PA-SS for carbohydrate detection; $\mathrm{HAg}, \mathrm{H}$ antigen of Histoplasma capsulatum; Pro, purified AP; S, molecular mass standards.

Although use of pepstatin A-agarose resulted in a purified AP product (Fig. $4 b$ ), recovery of AP activity was lower (specific activity, $150 \mathrm{U} \mathrm{mg}^{-1}$ ) relative to that obtained by anion exchange chromatography and gel filtration.

\section{Analysis for glycosylation of $A P$}

Purified AP was subjected to SDS-PAGE and stained with periodic acid-silver stain (PA-SS). PA-SS is reported (Tsai \& Frasch, 1982) to be 500-times more sensitive for carbohydrate detection than the PAS stain used by others (Rüchel, 1981; Negi et al., 1984; Ray \& Payne, 1990) and detects as little as $0.4 \mathrm{ng}$ carbohydrate (Dubray \& Bezard, 1982). Carbohydrate was demonstrated by the PA-SS method in a positive control glycoprotein, the $\mathrm{H}$-antigen of Histoplasma capsulatum, but not in purified AP (even when AP was overloaded onto the gel, Fig. 5). The absence of PA-SS-detectable carbohydrate in preparations of AP purified by our method indicates that if AP is glycosylated, it is at a very

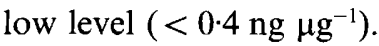

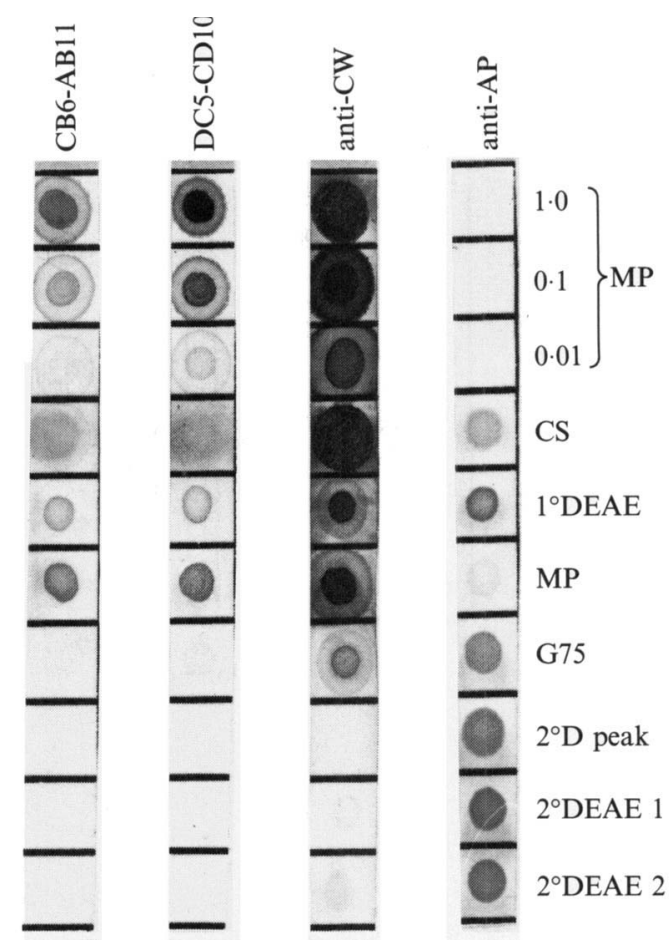

Fig. 6. Dot EIA of purification step products of AP from strain CBS 2730. Antigens from top to bottom: Purified cell wall MP $(1 \cdot 0,0 \cdot 1$ and $0.01 \mathrm{mg} \mathrm{ml}^{-1}$ ); unpurified culture supernatant (CS); primary DEAESephadex A25-purified AP ( $1^{\circ}$ DEAE); MP-containing peak from Sephadex G75 chromatography (MP); AP-containing peak from Sephadex G75 chromatography (G75); peak fraction of purified AP from secondary DEAE-Sephadex A25 chromatography $\left(2^{\circ} \mathrm{D}\right.$ peak); pooled peak fractions of AP from secondary DEAE-Sephadex A25 chromatography $\left(2^{\circ} \mathrm{DEAE} 1\right.$ and $2^{\circ} \mathrm{DEAE} 2$, separate runs). Strips (left to right) were tested with one of the following: CB6-AB11 or DC5-CD10 anti-MP mAbs, anti-CW (polyclonal anti-C. albicans cellwall $\mathrm{IgG}$ ) or anti-AP (polyclonal anti-AP IgG).

We also observed no effect on the molecular mass of AP (by SDS-PAGE), or any reduction in the generation of AP activity, when $C$. albicans blastoconidia were grown in the presence of tunicamycin $\left(0 \cdot 5-5 \cdot 0 \mu \mathrm{g} \mathrm{ml}^{-1}\right)$, an inhibitor of glycosylation (Duksin \& Mahoney, 1982) (data not shown).

Dot EIA of sequential products of AP purification steps.

Nitrocellulose strips were dotted with purified (Peat et al., 1961) cell wall MP or AP in progressive stages of purification and tested in dot EIA with one of the following: (a) CB6-AB11 (IgM) anti-MP mAb, (b) DC5CD10 (IgG) anti-MP mAb, (c) rabbit anti-C. albicans cell wall polyclonal IgG (anti-CW), or (d) mouse anti-AP polyclonal IgG (anti-AP). The results are shown in Fig. 6.

CB6-AB11 and DC5-CD10 monoclonal antibodies gave positive reactions with purified MP $(1 \cdot 0,0 \cdot 1$, and $0.01 \mathrm{mg} \mathrm{ml}^{-1}$ ), unpurified culture supernatant, primary 


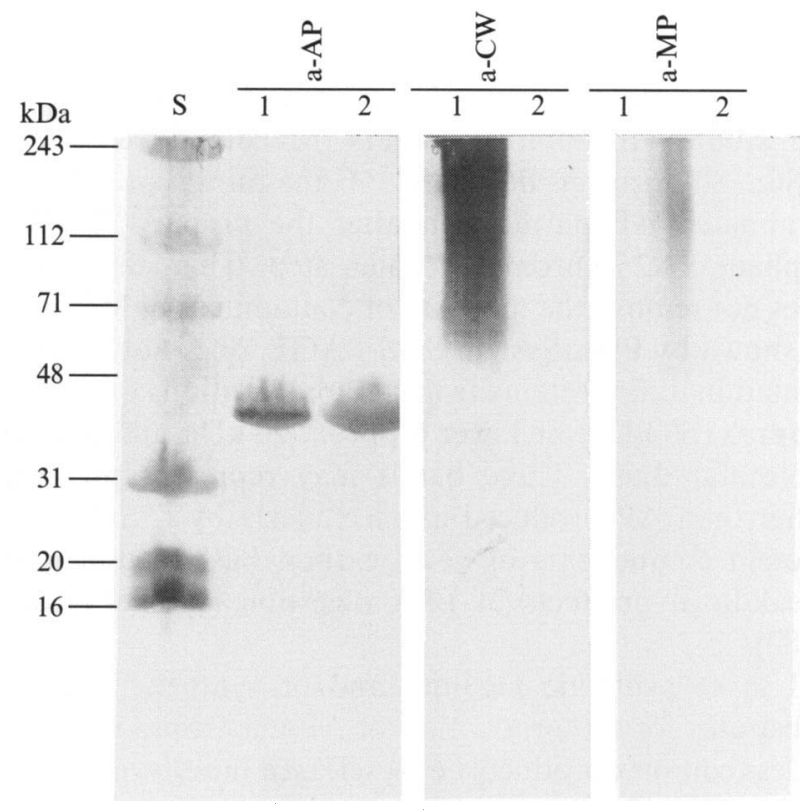

Fig. 7. Immunoblot analysis of unpurified culture supernatant and of purified AP from strain CBS 2730 as antigens tested with polyclonal anti-AP IgG (a-AP), anti-C. albicans cell-wall IgG (a-CW) or monoclonal anti-MP antibodies (DC5-CD10, a-MP). Lanes: 1, unpurified culture supernatant $\left(327 \mu \mathrm{g}\right.$ protein $\left.\mathrm{ml}^{-1}\right) ; 2$, purified AP $\left(305 \mu \mathrm{g}\right.$ protein $\left.\mathrm{ml}^{-1}\right)$. S, molecular mass standards.

DEAE-Sephadex A25-purified AP, and pooled fractions from the smaller, MP-containing peak from Sephadex G75 chromatography. Little or no reactivity with the larger, AP-containing peak from Sephadex G75 chromatography was observed using DC5-CD10 or CD6AB11 mAbs (Fig. 6). In addition, no reactivity with either $\mathrm{mAb}$ was observed against the peak fraction of secondary DEAE-Sephadex A25 purified AP or with pooled, concentrated peak fractions of secondary DEAE-Sephadex A25 purified AP from two separate runs.

Anti-CW antibodies reacted positively with purified MP and all products of AP purification up to and including the Sephadex G75 chromatographic step. Minor or no reactivity with anti-CW antibodies was observed for AP purified by secondary DEAE-Sephadex A25 chromatography (Fig. 6).

Anti-AP antibodies did not react with purified MP $\left(1.0,0.1\right.$ or $\left.0.01 \mathrm{mg} \mathrm{ml}^{-1}\right)$ and showed minor reactivity with the MP-containing peak from Sephadex G75 chromatography. Products of all subsequent purification steps reacted positively with anti-AP (Fig. 6). Thus, primary DEAE-Sephadex A25 chromatography alone, or in combination with Sephadex G75 chromatography, is not sufficient to remove immunoreactive carbohydrate and cell wall antigens from AP preparations. Addition of a secondary DEAE-Sephadex A25 column following primary DEAE-Sephadex A25 and Sephadex G75 chromatography is sufficient to remove immunoreactivity to MP. Anti-AP antibodies did not recognize MP $\left(1 \cdot 0,0 \cdot 1\right.$ or $\left.0.01 \mathrm{mg} \mathrm{ml}^{-1}\right)$, indicating that MP had been sufficiently removed from AP by our chromatographic series to prevent development of MP-reactive antibodies.

\section{Immunoblot analysis of AP for the presence of MP-or cell-wall-reactive components}

Western blot (immunoblot) analysis demonstrated the absence of detectable MP- or cell wall-reactive components in the final, purified AP preparation despite its presence in the unpurified culture supernatant (Fig. 7). MP and cell wall reactivity was observed as a diffuse smear at the top of the nitrocellulose strip when unpurified culture supernatant (lane 1 of each pair, Fig. 7) was tested with DC5-CD10 anti-MP mAbs (a-MP) or polyclonal anti-C. albicans cell wall $\operatorname{IgG}(\mathrm{a}-\mathrm{CW})$. This diffuse reactivity was similar to that observed for silver-stained polyacrylamide gels of the smaller, MP-containing peak obtained from Sephadex G75 chromatography described earlier. No such reactivity was observed in immunoblots of purified AP (lane 2 of each pair), indicating removal of reactive contaminants (Fig. 7).

\section{Discussion}

We describe the systematic purification and characterization of the extracellular AP from $C$. albicans. Unpurified culture supernatants contained significant amounts of contaminating cell wall MP which, unless removed, could interfere with the production of APspecific antibodies. This is especially important when questions regarding the detection of $\mathrm{AP}$ in infected tissues or body fluids, or on the surface of $C$. albicans cells are being addressed using antibodies raised against an impure AP preparation. Detection methods using multireactive antibodies could reflect reactivity to the contaminating MP rather than to AP itself. Indeed, reports describing AP as a glycoprotein that has PAS (Rüchel, 1981; Negi et al., 1984; Ray \& Payne, 1990) or carbohydrate positivity (Macdonald \& Odds, 1980) may be describing effects due to the presence of contaminating MP.

MP detection by sandwich EIA indicated that AP purified by our methods contained $0.6 \mathrm{ng}$ of MP ( $\mu \mathrm{g}$ protein $)^{-1}$. This concentration is less than $0.06 \%$ of the total purified product and confirms the efficient removal of contaminating MP from AP preparations. In addition, anti-AP antibodies did not react with purified MP in dot EIA, indicating that there is insufficient MP in our purified AP preparations to elicit MP-reactive antibodies.

The lack of PA-SS positivity for purified AP pre- 
parations suggests that AP is not glycosylated. Further, when $C$. albicans blastoconidia were grown in the presence of tunicamycin, an inhibitor of glycosylation (Duksin \& Mahoney, 1982), no reduction in the excretion or activity of AP was detected, nor was the molecular mass of AP different. Possibly, other strains of C. albicans exist that produce a glycosylated AP, but our data, generated with the standard proteinase test strain CBS 2730 (Rüchel et al., 1986) and two others (36B and B311), suggest that AP is either not glycosylated or is

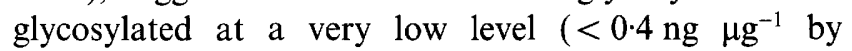
PA-SS). Rüchel et al. (1986) demonstrated that purified AP from $C$. albicans strain CBS 2730 did not bind concanavalin $\mathrm{A}$, indicating a lack of terminal glucose or mannose residues, and did not bind wheat-germ agglutinin, indicating a lack of terminal $\mathrm{N}$-acetylglucosamine residues. Further, although proteinase obtained from a strain of $C$. tropicalis reacted strongly in immunoblots with antibodies raised against mannan from $C$. albicans CBS 2730, these antibodies reacted only weakly with proteinase from C. albicans or C.parapsilosis and were considered to be non-specifically reactive (Rüchel et al., 1986). In addition, although there has been controversy regarding whether there are one or more secreted $C$. albicans proteinases and what role each may play (Hube et al., 1991, Morrow et al., 1992; Rüchel et al., 1992), one of the reported enzymes, from C. albicans ATCC 10231, does not appear to contain $\mathrm{N}$-glycosylation sites in the deduced amino acid sequence of the mature enzyme, whereas one such site occurs in the propeptide (Hube et al., 1991).

No reactivity with anti-MP mAbs and little or no reactivity with polyclonal anti-CW antibodies was observed in dot EIA against the final product of AP purification. No reactivity with either anti-MP mAbs or anti-CW antibody was observed by Western immunoblot versus purified AP. Given these results, the minor reactivity of purified, concentrated $\mathrm{AP}\left(2^{\circ} \mathrm{DEAE} 2\right)$ to anti-CW antibodies in dot EIA may be a non-specific artifact due to an excess amount of protein dotted $\left(635 \mu \mathrm{g} \mathrm{ml}^{-1}\right)$, compared with the peak purified fraction ( $2^{\circ} \mathrm{D}$ peak, $136 \mu \mathrm{g} \mathrm{ml}^{-1}$ ), which did not give a positive reaction. An alternative explanation may lie in the complex nature of the cell wall antigens used to raise anti-CW antibodies (Reiss et al., 1974). Indeed, immunoelectron microscopic studies have shown that AP is present in the cell wall of $C$. albicans yeasts (Ray \& Payne, 1991).

The original AP purification method of Remold et al. (1968) used a Sephadex G75 column followed by a series of two DEAE-Sephadex A25 columns. Although this purification scheme resulted in the recovery of a single AP band by gel electrophoresis, no analysis of the product was conducted to determine possible MP contamination (Remold et al., 1968). Use of Sephadex G75 first, followed by DEAE-Sephadex A25 chromatography, did not provide separation of MP from AP in our studies. In addition, others (Macdonald \& Odds, 1980; Shimizu et al., 1987; Ganesan et al., 1991) terminated AP purification after the primary DEAESephadex A25 chromatographic step. This step alone does not remove the majority of contaminating MP and, as shown by PhastSystem SDS-PAGE, does not remove contaminating proteins from AP preparations of higher (approx. $60 \mathrm{kDa}$ ) or lower (approx. $20 \mathrm{kDa}$ and below) molecular mass. These bands may represent proteins other than AP produced extracellularly by $C$. albicans, protein components of yeast carbon base medium, or breakdown products of BSA digestion (Rüchel et al., 1982).

Use of synthetic medium and/or synthetic peptide substrates for the production of AP may result in fewer or less complex products being released into the medium, making purification more straightforward. Poly-L- or poly-D-glutamate were used as substrates for AP production (Lerner \& Goldman, 1992), but no analysis of the purified product was described. To date, all studies on AP purification have used complex protein substrates. Ray \& Payne (1990) reported that keratin as a substrate resulted in cleaner AP preparations relative to other substrates. There may, however, be strains of $C$. albicans that are keratinolytic and those that are not. When keratin was used as a substrate in our system, we were unsuccessful in obtaining any significant AP production from C. albicans strains CBS 2730, B311, or 36B (Lam et al., 1991) even though the same keratin source as that of others was used (Ray \& Payne, 1990).

Our purification method resulted in high AP yields and high specific activities although absolute comparisons to the results obtained by others were often not possible. Although others used BSA as substrate for the extracellular production of AP in culture medium, the definition of a unit of enzyme activity was often based on the degradation of a different substrate (for example, haemoglobin or azocoll) rather than BSA, as in our studies.

Use of pepstatin A-agarose to purify AP resulted in a purified product with lower specific activity than that obtained by anion exchange chromatography and gel filtration. Alkaline conditions were necessary for the elution of AP from the pepstatin A column. Since alkalinity may denature AP and reduce its activity (Rüchel, 1981), exposure to alkaline conditions during pepstatin A-agarose purification might explain the loss of specific activity observed for AP purified by this method. Alternatively, bleeding of pepstatin from the column during elution may have contributed to a loss of detectable activity in the product although no attempt 
was made to determine whether pepstatin was present in the product.

Studies on the immunologic reactivity of AP should take into account the presence of other proteins and/or carbohydrates in AP preparations. The presence of contaminating MP in impure AP preparations could complicate studies to dissect the immunochemistry of moieties responsible for immune responsiveness, since MP may down-regulate the immune system (Domer \& Garner, 1989; Garner et al., 1990). In addition, MP and extraneous proteins in AP preparations could interfere with studies to understand the role of AP in pathogenesis.

Use of a single DEAE-Sephadex A25 column to purify AP is not sufficient to remove extraneous proteins or carbohydrate. Contaminating carbohydrate and nonpepstatin A-binding proteins should be removed from AP preparations before use in the production of polyclonal antibodies or, at the very least, contaminantreactive antibodies should be removed by adsorption or other means.

Strain-specific proteolytic capacities have been described for extracellular aspartyl proteinases (Rüchel et al., 1982). In addition, Rüchel et al. (1992) found strainspecific amino acid sequences for proteinases from each of two strains of $C$. albicans. More recently, however, each of these $C$. albicans strains was shown to contain two genes for aspartyl proteinases (Wright et al., 1992). One gene was expressed at a much higher level than the other under conditions of proteinase induction (Wright et al., 1992). The other gene may encode a proteinase functionally different from the secreted AP (Morrow et al., 1992). Further complexity is indicated by the finding that at least four forms of the proteinase described by Hube et al. (1991) can be distinguished by RFLP analysis of genomic DNA (Miyasaki et al., 1992). We have evidence that AP can be produced in more than one extracellular form by each of several strains of $C$. albicans. This finding will be reported separately.

\section{References}

ANDERSON, M. L. \& ODDS, F. C. (1985). Adherence of Candida albicans to vaginal epithelia: significance of morphological form and effect of ketoconazole. Mycosen 28, 531-540.

Barnes, J. L., Osgood, R. W., Lee, J. C., King, R. D. \& Stein, J. H. (1983). Host-parasite interactions in the pathogenesis of experimental renal candidosis. Laboratory Investigation 49, 460-467.

BRADFORD, M. (1976). A rapid and sensitive method for the quantitation of microgram quantities of protein utilizing the principle of protein-dye binding. Analytical Biochemistry 72, 248-254.

CRANDALl, M. \& EDWARDS, J. E., JR (1987). Segregation of proteinasenegative mutants from heterozygous Candida albicans. Journal of General Microbiology 133, 2817-2824.

DOMER, J. E. \& GARNER, R. E. (1989). Immunomodulation in response to Candida. Immunology Series 47, 293-317.

Dubray, G. \& BEZARD, G. (1982). A highly sensitive periodic acid-silver stain for 1,2-diol groups of glycoproteins and polysaccharides in polyacrylamide gels. Analytical Biochemistry 119, $325-329$.
Duksin, D. \& Mahoney, W. C. (1982). Relationship of the structure and biological activity of the natural homologues of tunicamycin. Journal of Biological Chemistry 257, 3105-3109.

Ganesan, K., BanerJee, A. \& Datta, A. (1991). Molecular cloning of the secretory acid proteinase gene from Candida albicans and its use as a species-specific probe. Infection and Immunity 59, 2972-2977.

Garner, R. E., Childress, A. M., Human, L. G. \& Domer, J. E. (1990). Characterization of Candida albicans mannan-induced, mannan-specific delayed hypersensitivity suppressor cells. Infection and Immunity 58, 2613-2620.

Ghannoun, M. A. \& Abu Elteen, K. (1986). Correlative relationship between proteinase production, adherence, and pathogenicity of various strains of Candida albicans. Journal of Medical and Veterinary Mycology 24, 407-413.

Hellwege, W. H., Fischer, K. \& Blaker, F. (1972). Diagnostic value of Candida precipitins. Lancet 2, 386.

Hube, B., Turver, C. J., Odds, F. C., Eiffert, H., Boulnois, G. J., KoCHEL, H. \& RÜCHEL, R. (1991). Sequence of the Candida albicans gene encoding the secretory aspartate kinase. Journal of Medical and Veterinary Mycology 29, 129-132.

Kaufman, L. \& ReISs, E. (1992). Serodiagnosis of fungal diseases. In Manual of Clinical Immunology, 4th edn, pp. 506-528. Edited by N. R. Rose, E. C. de Macario, J. L. Fahey, H. Friedman \& G. M. Penn. Washington, DC: American Society for Microbiology.

Kregar, I., Urh, I., Umezawa, H. \& TURK, V. (1977). Purification of cathepsin D by affinity chromatography on pepstatin sepharose column. Croatica Chemica Acta 49, 587-592.

Kwon-Chung, K. J., Lehman, D., Good, C. \& Magee, P. T. (1985). Genetic evidence for role of extracellular proteinase in virulence of Candida albicans. Infection and Immunity 49, 571-575.

Lam, M., Peterkin, V., Reiss, E. \& Morrison, C. J. (1991). Effect of growth conditions on the extracellular production of the aspartic proteinase by Candida albicans. Advances in Experimental Medicine and Biology 306, 265-267.

LERNER, C. G. \& GoldMAN, R. C. (1992). Environmental stimuli that induce production of Candida albicans extracellular aspartyl proteinase. Abstracts of the 92nd Annual Meeting of the American Society for Microbiology 1992, abstract F-51, p. 507.

McCourtie, J. \& Douglas, L. J. (1984). Relationship between cell surface composition, adherence, and virulence of Candida albicans. Infection and Immunity 45, 6-12.

MACDonald, F. \& ODDS, F. C. (1980). Inducible proteinase of Candida albicans in diagnostic serology and the pathogenesis of systemic candidosis. Journal of Medical Microbiology 13, 423-435.

MiYasaki, S. H., White, T. C. \& Agabian, N. (1992). Genomic organization and transcriptional regulation of the Candida albicans secreted acid protease gene. Conference on Fungal Dimorphism, Cambridge, UK, September 2nd, 1992, abstract P18, pp. 218-219.

Morrison, A. J., Jr., Freer, C. V., Searcy, M. A., Landry, S. M. \& WENZEL, R. P. (1986). Nosocomial bloodstream infections: secular trends in a statewide surveillance program in Virginia. Infection Control 7, 550-553.

Morrow, B., Srikantha, T. \& Soll, D. R. (1992). Transcription of the gene for a pepsinogen, PEP1, is regulated by white-opaque switching in Candida albicans. Molecular and Cellular Biology 12, 2997-3005.

Negi, M., Tsuboi, R., Matsui, T. \& Ogawa, H. (1984). Isolation and characterization of proteinase from Candida albicans: substrate specificity. Journal of Investigative Dermatology 83, 32-36.

ODDS, F. C. (1988). Factors that predispose the host to candidosis. In Candida and Candidosis, 2nd edn, pp. 93-114. London: Bailliere Tindall.

Peat, S., Whalen, W. J. \& Edwards, T. E. (1961). Polysaccharides of baker's yeast. IV. Mannan. Journal of the Chemical Society (London) $29-34$.

RAY, T. \& PAYNE, C. D. (1990). Comparative production and rapid purification of Candida acid proteinase from protein-supplemented cultures. Infection and Immunity 58, 508-514.

RAY, T. \& PAYNe, C. D. (1991). Candida acid proteinases: characterization and role in candidiasis. Advances in Experimental Medicine and Biology 306, 173-183.

Reingold, A. L., Lu, X. D., Plikaytis, B. D. \& Ajello, L. (1986) 
Systemic mycoses in the United States, 1980-1982. Journal of Medical and Veterinary Mycology 24, 433-436.

Reiss, E., Stone, S. H. \& Hasenclever, H. F. (1974). Serological and cellular immune activity of peptidoglucomannan fractions of Candida albicans cell walls. Infection and Immunity 9, 881-890.

Reiss, E., Hutchinson, H., Pine, L., Ziegler, D. W. \& Kaufman, L. (1977). Solid-phase competitive binding radioimmunoassay for detecting antibody to the $\mathrm{M}$ antigen of histoplasmin. Journal of Clinical Microbiology 6, 598-604.

Reiss, E., De Repentigny, L., Kuykendall, R. J., Carter, A. W., Galindo, R., Auger, P., BragG, S. L. \& Kaufman, L. (1986). Monoclonal antibodies against Candida tropicalis mannan: antigen detection by enzyme immunoassay and immunofluorescence. Journal of Clinical Microbiology 24, 796-802.

Remold, H., Fasold, H. \& Staib, F. (1968). Purification and characterization of a proteolytic enzyme from Candida albicans. Biochimica et Biophysica Acta 167, 399-406.

RiCHARDSON, M. D. (1991). Opportunistic and pathogenic fungi. Journal of Antimicrobial Chemotherapy 28, suppl. A, 1-11.

Ross, I. K., De Bernardis, F., Emerson, G. W., Cassone, A. \& Sullivan, P. A. (1990). The secreted aspartate proteinase of Candida albicans: physiology of secretion and virulence of a proteinasedeficient mutant. Journal of General Microbiology 136, 687-694.

RüCHEL, R. (1981). Properties of a purified proteinase from the yeast Candida albicans. Biochimica et Biophysica Acta 659, 99-113.

RüCHEL, R. \& BöNING, B. (1983). Detection of Candida proteinase by enzyme immunoassay and interaction of the enzyme with alpha-2macroglobulin. Journal of Immunological Methods 61, 107-116.

RüChel, R., Tegeler, R. \& TROST, M. (1982). A comparison of secretory proteinases from different strains of Candida albicans. Sabouraudia 20, 233-244.

RÜCHEL, R., BöNING, B. \& BORG, M. (1986). Characterization of a secretory proteinase of Candida parapsilosis and evidence for the absence of enzyme during infection in vitro. Infection and Immunity 53, 411-419.

RÜCHel, R., BöNING-STUTZER, B. \& MarI, A. (1988). A synoptical approach to the diagnosis of candidosis, relying on serological antigen and antibody tests, on culture, and on evaluation of clinical data. Mycoses 31, 87-106.

Rüchel, R., De Bernardis, F., Ray, T. L., Sullivan, P. A. \& Cole,
G. T. (1992). Candida acid proteinases. Journal of Medical and Veterinary Mycology 30, Suppl 1, 123-132.

Sartorelli, A. C., Fischer, D. S. \& Downs, W. G. (1966). Use of sarcoma 180/TG to prepare hyperimmune ascitic fluid in the mouse. Journal of Immunology 96, 676-682.

ShimizU, K., KondoH, Y. \& TANaKa, K. (1987). Proteinase production and pathogenicity of Candida albicans. I. Invasion into chorioallantoic membrane by $C$. albicans strains of different proteinase activity. Microbiology and Immunology 31, 1045-1060.

StaIB, F. (1969). Proteolysis and pathogenicity of Candida albicans strains. Mycopathologia et Mycologia Applicata 37, 345-348.

Taschdian, C. L., Seelig, M. S. \& KozinN, P. J. (1973). Serological diagnosis of candidiasis. Critical Reviews in Clinical Laboratory Sciences 4, 19-60.

Todaro-Luck, F., Reiss, E., Cherniak, R. \& Kaufman, L. (1989). Characterization of Cryptococcus neoformans capsular glucuronoxylomannan polysaccharide with monoclonal antibodies. Infection and Immunity 57, 3882-3887.

TSAI, C.-M. \& FraSCH, C. E. (1982). A sensitive silver stain for detecting lipopolysaccharides in polyacrylamide gels. Analytical Biochemistry 119, $115-119$.

Tsang, V. C. W. (1987). The enzyme-linked immuno-electrotransfer blot ('Western blot'): technical considerations. In Integration and Control of Metabolic Processes: Pure and Applied Aspects, pp. 489-500. Edited by O. L. Kon, M. C.-M. Chung, P. L. H. Hwang, S.-F. Leong, K. H. Loke, P. Thiyagarajah \& P. T.-H. Wong. Cambridge: ICSU Press (Cambridge University Press).

Tsang, V. C. W., Peralta, J. M. \& Simons, A. R. (1983). Enzymelinked immuno-electro-transfer blot techniques (EITB) for studying the specificities of antigens and antibodies separated by gel electrophoresis. Methods in Enzymology 92, 377-391.

Tsang, V. C. W., Hancock, K., Wilson, M., Palmer, D. F., Whaley, S. D., McDougal, J. S. \& KennedY, S. (1986). Enzyme-linked immunoelectrotransfer blot technique (Western blot) for human T-lymphotropic virus type III/lymphadenopathy-associated virus (HTLV-III/LAV) antibodies. Immunology Series No. 15. Procedural Guide. Atlanta, GA, USA: Centers for Disease Control.

Wright, R. J., CARne, A., Hieber, A. D., Lamont, I. L., EMerson, G. W. \& Sullivan, P. A. (1992). A second gene for a secreted aspartate proteinase in Candida albicans. Journal of Bacteriology 174, 7848-7853. 